\title{
LEITURA DE PAULO FREIRE COM INFÂNCIAS: TRAJETOS CASAS-ESCOLA COMO TEMA GERADOR DO CONHECIMENTO
}

\author{
PAULO FREIRE'S READING OF CHILDHOODS: SCHOOL-HOUSE PATHS AS KNOWLEDGE-GENERATING \\ THEME
} LECTURA DE PAULO FREIRE CON INFANCIAS: TRAYECTOS CASAS-ESCUELA COMO TEMA GENERADOR
DEL CONOCIMIENTO

\author{
BAIERSDORF, Márcia ${ }^{1}$ \\ CAMPOS, Marília Torales²
}

\section{RESUMO}

Esse artigo objetiva denotar a construção de um currículo culturalmente integrado, atento ao modo como as crianças pronunciam sua realidade. Para isso, evoca o universo temático de um grupo de alunos em seus trajetos da casa para uma escola de Ensino Fundamental - Anos Iniciais. Os dados selecionados para a análise proveem de pesquisa conduzida com a participação infantil e expressam a relação com o lugar onde moram e estudam. A leitura de Freire (1987) com os dizeres e fotografias das crianças esclarece a experiência sociocultural que perpassa o desvelamento do cotidiano, do qual o tema gerador do conhecimento se anuncia.

Palavras-chave: Paulo Freire. Infâncias. Cotidiano. Tema Gerador.

\section{ABSTRACT}

This article denotes the construction of a culturally integrated curriculum, attentive to the way that children pronounce their reality. In order to do so, it evokes the thematic universe of a group of students on their way from yours home to an Elementary School. The data selected for analysis provide research conducted with child participation and express the relationship with where they live and study. The reading of Freire (1987) with the words and photographs of children clarifies the social and cultural experience that permeates the unveiling of everyday life, from where the generating theme of knowledge is announced.

Keywords: Paulo Freire. Childhood. Daily. Generator Theme.

\section{RESUMEN}

Este artículo objetiva denotar la construcción de un currículo culturalmente integrado, atento al modo como los niños pronuncian su realidad. Para ello, evoca el universo temático de un grupo de alumnos en sus trayectos de la casa a una escuela de Enseñanza Fundamental - Años Iniciales. Los datos seleccionados a analisis provienen de investigación conducida con la participación infantil y expresan la relación con el lugar donde viven y estudian. La lectura de Freire (1987) con los textos y fotografías de los niños esclarece la experiencia sociocultural que atraviesa el desvelamiento de lo cotidiano, de donde el tema generador del conocimiento se anuncia.

Palabras clave: Paulo Freire. Infancia. Cotidiano. Tema Generador.

\footnotetext{
1 Universidade Federal do Paraná - UFPR - Paraná - Brasil

2 Universidade Federal do Paraná - UFPR - Paraná - Brasil
} 


\section{INTRODUÇÃO}

Este artigo apresenta referentes culturais ${ }^{3}$ levantados por alunos de uma escola de Ensino Fundamental - Anos Iniciais ${ }^{4}$, a partir dos quais o pensar das crianças sobre a própria realidade existencial pode ser vislumbrado como fonte profícua de um currículo escolar culturalmente integrado5. Acompanhando-os foi possível trazer à discussão uma gama de possibilidades de ressignificação dos trajetos entre a casa e a escola, particularmente quanto à potência da experiência escolar extramuros, dedicada ao desvelamento do cotidiano para além da vivência.

Os dados apresentados neste artigo tiveram sua origem em uma pesquisa ${ }^{6}$ mais ampla sobre a configuração de um ensino diversificado ${ }^{7}$, a qual esteve reportada ao debate em torno da Educação Integral, especificamente no que se refere à compreensão da experiência de mais tempo de escola à luz do desvelamento do cotidiano (HELLER, 1977; EZPELETA, 1989; DUBET, 1994; ROCKWELL, 1997) e com base na experiência sociocultural de um grupo de crianças (FREIRE, 1987, 1999; KRAMER, 2002; BENJAMIN, 2002, 2013, 2015 e LARROSA, 2002, 2015), ambas as categorias de análise evocadas como chaves de significação do conhecimento escolar.

Os referentes culturais apontados pelas crianças foram interpretados segundo a discussão metodológica de Paulo Freire (1987), para quem a mobilização social em torno de uma dada realidade engendra possibilidades de diálogo entre a experiência educativa e a riqueza cultural das pessoas e de um lugar, conduzindo temas geradores de aprendizagens sociais mediadas pela escola.

Em sua obra, Pedagogia do Oprimido, editada no final da década de 1960, Freire aponta para o desvelamento de temas recorrentes, disputados numa dada temporalidade. São temas originados de situações limites de uma realidade e que ensejam transformações na escola e na sociedade. Afirma que, na prática social, os sujeitos históricos agem em busca do direito de sermos mais e, nesse processo, as tensões próprias de uma época emergem, "não como a fronteira entre o ser e o nada, mas como a fronteira entre o ser e o mais ser [...] percepção em que está implícito o inédito viável" (FREIRE, 1987, p.53). E, é com base nesta perspectiva cultural que se alicerçou a análise dos dados sobre a experiência de uma escola empenhada em produzir práticas educativas com uso de tempos e espaços ampliados, a partir de sua adesão ao Programa Federal Mais Educação (PME) ${ }^{8}$.

\footnotetext{
${ }^{3}$ Estamos compreendendo referentes culturais como eventos relacionados ao contexto sociocultural das crianças, capturados a partir de situações cotidianas dos alunos, de sua escola e do lugar onde vivem.

${ }^{4}$ Escola Municipal Rural da Capoeira dos Dinos (Piraquara, Paraná).

${ }^{5}$ Dimensão da educação integral representativa da potência de uma escola capaz de baixar seus próprios muros por meio da relação entre os conteúdos tornados objeto de escolarização e os referentes culturais da comunidade a qual pertence.

${ }^{6}$ Notas para uma educação integral: participação das crianças da Região da Capoeira dos Dinos (PR) para a construção da experiência de mais tempo da escola em que estudam.

${ }^{7}$ A pesquisa compreendeu como diversificação cultural do ensino as transformações substanciais na forma e no conteúdo da escola regular, relativas à superação da precariedade da educação de massa e à democratização do conhecimento e da sociedade.

8 O PME previa a transferência voluntária de recursos da União em apoio a atividades socioeducativas no contra turno escolar. Foi instituído pela Portaria Interministerial n¹7/2007 e pelo Decreto Presidencial n 7083/2010. Em 2016 foi substituído pelo Programa Novo Mais Educação que por meio da Portaria Interministerial n 1.144/2016 reduziu sua abrangência focando apenas em escolas identificadas como de baixa eficácia.
} 
Utilizando-se da observação circunstanciada em escola 9 (EZPELETA, 1989; ROCKWELL, 1997; GARCIA, 2011), a pesquisa foi ao encontro das crianças, tornando-as participantes (KRAMER, 2002; BENJAMIN, 2002; 2013; 2015) na produção dos dados. Elas foram entrevistadas e convidadas a avaliarem as experiências de mais tempo de escola.

Para que registrassem suas leituras do mundo ${ }^{10}$ Ihes foram disponibilizadas máquinas fotográficas e solicitado que elas contassem através das imagens como era o dia a dia na região onde vivem, moram e estudam. Com esse convite, elas trouxeram suas contribuições e assim a pesquisa pode apreender os rastros de experiências vividas para além da escola, capturadas em falas significativas ${ }^{11} \mathrm{e}$ em fotografias produzidas por elas mesmas.

As imagens e depoimentos foram transcritos e ordenadas segundo onze categorias, inventariadas de acordo com os dizeres infantis sobre: lugares; pessoas; bichos; atividades; objetos; autoimagem; acontecimentos; trajetos; plantas; trabalho dos adultos; e o céu. Ao registro das falas sobre trajetos, foram acrescentados informes das rotas escolares, acompanhadas durante uma semana letiva com as crianças.

Paralelamente a esse levantamento, foram acessadas fontes documentais, dentre as quais o audiovisual Conhecendo Piraquara, acervo didático produzido no ano de 2007 numa ação formativa da Secretaria Municipal de Educação, o qual reunia histórias de moradores da região onde esta localizada a escola, bem como de outras localidades do município. O contato com essa fonte permitiu que a pesquisa acessasse aspectos de um passado recente das crianças, e assim, acrescentasse aos referentes culturais por elas levantados, componentes históricos implicados na vida cotidiana.

Para esse artigo foram recortados apenas os referentes culturais descritos como lugares e ônibus/trajetos, relativos aos percursos das crianças entre as casas e a escola, estes, cotejados pelo audiovisual que havia rememorado a fala de moradores antigos da região. Com esse recorte, indagamos se as falas e imagens capturadas não estariam anunciando inéditos viáveis de um ensino diversificado, constituindo-se em fontes de uma experiência escolar culturalmente integrada.

\section{PARA RESSIGNIFICAR O COTIDIANO: DISCUSSÃO DOS DADOS DA PESQUISA}

Mas o que pudemos apreender percorrendo com as crianças seus caminhos? Seria viável construir uma narrativa do cotidiano dessa localidade que pudesse transcender a simples vivência rotineira? Como a descrição de trajetos/ônibus diários, repetitivos, banais, corriqueiros poderia se converter em instrumento de leitura crítica daquela realidade?

\footnotetext{
${ }^{9}$ A investigação de abordagem etnográfica teve uma inserção de dois anos letivos em uma escola pública da área rural do município de Piraquara/PR, porém a observação participante não se deu exclusivamente dado o envolvimento das crianças na produção dos dados.

${ }^{10}$ A prática educativa em Freire se constrói com os grupos populares e não para eles, daí que a leitura do mundo se refira aos processos de conhecimento e saberes vividos anteriores à leitura da palavra escrita ou à forma escriturária do ensino convencional.

${ }^{11} \mathrm{~A}$ busca do tema gerador inicia pelo levantamento do universo temático que reunirá as falas significativas de um grupo, registradas como elementos de codificação da realidade a ser problematizada, expressas em palavras, imagens e temas que se tornam objetos de estudo e de mobilização social em torno do conhecimento.
} 
Ao encontro dessas indagações, a pesquisa desenvolveu uma leitura de contraposição àquilo que Heller (1987) chamou de crítica negativa do cotidiano, para a qual faltaria referenciar um campo antropológico e histórico maior. Como aquele corroborado pela abordagem de Freire (1987) através de seus temas/palavras geradoras do conhecimento, por meio dos quais a educação popular assume para si a tarefa de mediar um diálogo epistemológico e político com as pessoas, inseridas em seus contextos existenciais concretos, cujas linguagens e pensares se constituem, justamente, na relação com as condições estruturais da realidade em que se encontram.

Os temas geradores expressam essa mobilização e assim consubstanciam uma pedagogia da pergunta, cujo conteúdo programático não se encontra estagnado nem a priori, ao contrário se oferece aos sujeitos históricos como sistematizações de respostas buscadas frente aos desafios do presente, tanto no nível intelectual como no nível da ação política. Por essa abordagem, em diálogo com o pensar das crianças e atenta a suas linguagens, a pesquisa se valeu do cotidiano como chave de leitura da experiência sociocultural ${ }^{12}$ das crianças.

Para avançar desde esse ponto, o campo antropológico proposto na Pedagogia de Freire (1987) dialogou com Benjamin (2013) que acrescenta à experiência o valor da narrativa e, com Larrosa (2015) reconheceu a confluência de acontecimentos modificadores do rumo de uma vida, circunstância que qualifica a experiência como formativa, por quanto se assenta na transformação da subjetividade daquele ou daquela que participa do processo educativo. Nesse processo, os grupos populares passam a se reconhecer como parte de uma realidade social dinâmica e na qual é possível intervir para transformá-la.

Dentro dessa compreensão, ativemo-nos às narrativas das crianças, escutando-as no papel de quem produz memória e de quem, ao fazê-lo, põe em interação passado, presente e futuro. Nesse sentido, os relatos e imagens infantis remeteram a experiência social que as atravessam e que ao mesmo tempo as transcendem.

Imbuídos de suas histórias e da cultura local, lemos em suas narrativas indícios de uma experiência social intensa, reconhecida na expressão das diferentes infâncias ali vivenciadas. Em diálogo com a curiosidade das crianças sobre o mundo, encontramos vestígios das mudanças e das continuidades experimentadas por elas e suas famílias na relação com o presente e o passado daquela localidade.

\section{CONHECENDO PIRAQUARA}

O município de Piraquara fica a Leste de Curitiba, distando $22 \mathrm{~km}$ da capital paranaense. É um município estratégico para o desenvolvimento da região metropolitana, pois abriga áreas de preservação ambiental devido aos seus mananciais de água. A escola em que ocorreu a pesquisa está circunscrita a uma dessas áreas, em uma região conhecida como Capoeira dos Dinos, nome que referencia as características ambientais do lugar e o sobrenome de uma das famílias que lá residia.

\footnotetext{
${ }_{12}$ Correspondente ao referido campo histórico e antropológico que configura o universo temático buscado pela Pedagogia do Oprimido, para a qual a ação educativa é sempre dialógica, por isso mesmo o sujeito não é mero expectador.
} 
Essa distribuição espacial remonta algo dos deslocamentos humanos que marcaram o crescimento da cidade ao longo do tempo, desde sua origem, entre 1880 e 1885, quando das obras da estrada de ferro Paranaguá-Curitiba e, posteriormente, na década de 1950, com a abertura da Rodovia do Encanamento, na direção leste de Curitiba passando pelo município de Pinhais. Esses eixos rodoviários foram desviando o núcleo original de povoamento para outras áreas de urbanização.

No audiovisual Conhecendo Piraquara, um morador mais antigo, de sobrenome Batista, rememorou essa história, explicando o relativo isolamento espacial da região da Capoeira dos Dinos e do próprio município em relação a capital paranaense,

\begin{abstract}
Quando teve a construção da estrada de ferro os colonos começaram cada um a formar um carro de boi. Muitos foram daqui pra Piraquara e para São José [dos Pinhais]. Foi decaindo a Colônia [Santa Maria]. Porque a estrada de ferro era pra ter passado aqui e migraram pra Piraquara [a cidade] porque brigaram por dinheiro. Daí, eles furaram o túnel de Roça Nova [na altura da linha férrea]. Muitos colonos foram debandando e formando chácara em redor de Piraquara [atual Região da Sede Municipal]. Cresceu ali um pequeno comércio. Mas Piraquara ficou uma cidade fechada porque os políticos não queriam abrir a Estrada do Encanamento [que liga o município ao leste de Curitiba, na direção da cidade de Pinhais]. E os colonos não podiam vender lenha para Curitiba. Porque a estrada de ferro aí do pé da Serra precisava de muita lenha pra puxar a carga de Paranaguá para Curitiba. Depois entrou a gasolina e a estrada não precisava de tanta lenha. Foi indo até que abriram a Estrada do Encanamento. E Piraquara começou a crescer [principalmente na divisa com Pinhais, na Região do Guarituba a qual atualmente concentra mais da metade da população que é de 106.132 habitantes, segundo o IBGE (2016)].
\end{abstract}

Hoje a região da Capoeira dos Dinos permanece uma área rural e está distante dos pontos de urbanização mais intensa e das ocupações irregulares incidentes no município. A escola pesquisada dista cerca de 10 km da região da Sede Municipal - Prefeitura e Câmara de Vereadores. Recebe crianças advindas de perímetros circundantes, desde a linha férrea que corta o centro da cidade até as imediações da BR 277, sentido litoral paranaense, na divisa com os municípios de São José dos Pinhais e Morretes. No período em que se deu a investigação, recebia cerca de 80 alunos que dependiam do transporte escolar para estudar.

\title{
PERCORRENDO AS ROTAS DO TRANSPORTE ESCOLAR
}

As famílias vivem em pequenas vilas, chácaras, aras e casas isoladas, de modo que o tempo de acesso até a escola consistia em uma rotina diária bastante exaustiva, uma vez que a espera dos alunos desde o translado no ônibus chegava a ser $2 \mathrm{~h} 45$ para oito crianças e 80 min para as demais.

A primeira viagem iniciava por volta das $6 \mathrm{~h}$, com o dia ainda escuro. As crianças aguardavam na estrada, acompanhadas por seus responsáveis. Eram crianças que moravam nas vilas Pica-pau e Roça Nova. No turno da tarde os itinerários se repetiam, com os últimos alunos da manhã retornando por volta das $13 \mathrm{~h}$ às suas casas. No circuito do meio-dia, ocorria o regresso dos alunos da manhã e o ingresso dos alunos da tarde, o que propiciava o encontro entre os turnos. Na última rota do dia retornavam as suas casas até às $18 \mathrm{~h} 45$.

O transporte escolar seguia duas rotas distintas - Mananciais da Serra e Santa Maria. Os pontos de parada eram demarcados pela prefeitura em comum acordo com as famílias. As rotas 
margeavam a Barragem, nos limites do Centro de Educação Ambiental da SANEPAR ${ }^{13}$, momento em que os itinerários se encontravam na estrada de acesso a Colônia Santa Maria.

Entre 2014 e 2016, havia a oferta de atividades no turno escolar contrário, das quais participavam 45 crianças. A escola tratava essa oferta como parte do Projeto Mais Educação ${ }^{14}$, uma vez que ocorria naquele momento, no município, a adesão ao referido Programa Federal. Para essas crianças, o cansaço ao longo do dia era maior, especialmente para aquelas que eram as primeiras a serem pegas ou as últimas a retornarem, já com o dia anoitecido.

\section{ENTRE OS TEMPOS DE ESPERA E A VALORIZAÇÃO DA ESCOLA}

$\mathrm{Na}$ análise dos tempos de espera e de chegada até a escola, destacamos o empenho das crianças e de suas famílias em relação à frequência escolar. Os caminhos percorridos nas bifurcações eram estreitos, de terra e nos dias de chuva, difíceis de atravessar. Além disso, uma vez na escola também era preciso esperar.

A diretora já havia relatado o cansaço dos alunos e afirmado que o itinerário estabelecido dificultava adequações de horário, requeridas quando do planejamento e da execução das atividades do PME. $\mathrm{O}$ atendimento em tempo integral estava condicionado ao horário fixo do transporte ofertado pela prefeitura e acabava por sujeitar os alunos a turnos exaustivos, principalmente para os mais jovens. Situação que criava dificuldades para a escola planejar atividades extramuros ou promover, em razão de demandas do trabalho pedagógico, reordenamentos criativos dos tempos e espaços escolares.

Nesse contexto, o ônibus servia quase que exclusivamente para fazer o deslocamento no trajeto casas-escola. Somente em casos esporádicos era utilizado para passeios. De outro lado, poucas vezes a escola fez uso do artifício de levar os alunos para atividades locais a pé mesmo, entre outros motivos, porque o acesso a equipamentos públicos na região era restrito.

As distâncias dificultavam chegar aos pontos de cultura que talvez pudessem ser mapeados com as crianças em práticas escolares extramuros. Consequentemente, a rotina das crianças consistia em adaptar-se ao ir e vir rotineiro e a experiência de mais tempo acabava limitada a edificação escolar. Fora dos limites intramuros, o ônibus ${ }^{15}$, acabava sendo o único componente de mais tempo a romper com essa regularidade, porém de um modo também padronizado em rotas e horários fixos.

Apesar disso, as crianças registraram suas referências de localização, destacaram as paisagens consideradas bonitas e verbalizaram apreciar o fato de que podiam interagir durante os percursos - cantando, acenando para quem subia ou descia, como mostrou uma delas, de nome fictício Ângela,

\footnotetext{
13 Companhia de saneamento básico do estado do Paraná.

14 A adesão ao PME seguiu a forma como a escola o compreendia, um projeto que viria para complementar o trabalho pedagógico em curso centrado na experiência escolar intramuros.

15 Convidados a atribuir um valor numérico para o componente educativo ônibus, numa escala de 0 a 100 , a nota média dada por 22 alunos respondentes foi de 45 pontos, ou seja, uma experiência considerada insuficiente.
} 
Eu tirei minhas fotos todas de dentro do ônibus. O caminho para a escola. A maioria das fotos eu tirei quando achava alguma coisa bonita. A represa que eu passo todo dia e as árvores que na foto ficaram todas embaraçadas. (Ângela, $2^{\circ}$ ano).

Chegando à escola, aguardavam na Biblioteca, espaço que também se tornava uma oportunidade de convívio e de diálogo entre pares. Como na descrição abaixo, ilustrativa da movimentação gerada pela chegada das crianças numa das manhãs letivas, durante a qual emergiu mais uma coletânea das suas histórias de pertença social,

\begin{abstract}
Dois meninos conversam empolgados sobre a festa da Roça Nova que tinha sido no domingo, quando duas irmãs se juntam à conversa. Um deles diz que por um número não ganhou um cavalo no bingo, enquanto o outro explica que não foi porque 'o pai tá economizando para ir à festa da igreja matriz [no centro da cidade] que tem mais prêmios'. As irmãs dizem que 'quase deu problema', porque o tio do menino que quase ganhou um cavalo por um fio não brigou, o que seria covardia porque ele é muito forte [...] Outro menino esclarece que o prêmio não era o cavalo, mas um passeio a cavalo. Aí as irmãs concordaram e uma delas acrescentou: 'por um triz não ganhei também'. (Diário de Campo, 2015).
\end{abstract}

Como se nota, entre o tempo de translado e a espera na biblioteca até que o dia letivo começasse ou terminasse um conjunto de práticas extraescolares havia se tornado mais um episódio do cotidiano, propiciado na comunicação entre as crianças. Nessas dinâmicas, o vivido entre a casa e a escola se fazia presente de um modo muito próprio daquele grupo, daquela escola e daquele lugar e colocava de manifesto os aspectos fundamentais de seus referentes culturais.

\title{
O ÔNIBUS COMO COMPONENTE CURRICULAR
}

Os dados da pesquisa mostravam que em torno da questão da mobilidade espacial havia um rico repertório disponível à codificação do cotidiano das crianças. Desde a referência aos lugares percorridos e frequentados, passando pelos pontos dos itinerários, e as histórias de um passado recente e de um presente e futuro corriqueiros.

Em face desse repertório, o ônibus se converteu em um componente educativo considerável, pois ao mesmo tempo em que atendia a necessidade de mobilidade, era ele próprio uma experiência de convívio favorável à compreensão crítica dos caminhos diariamente percorridos. Assim, ao utilizá-lo as crianças demarcavam seus lugares de preferência e demostravam o próprio senso de localização.

Desse contexto, a pesquisa mapeou o universo cultural do lugar, a partir de agora descrito com maior detalhamento e em continuidade com a leitura de Paulo Freire com as infâncias da Capoeira dos Dinos.

Começando pelos lugares evocados - a casa, o quintal, o gramado de brincar, a rua esburacada, a escola, as paisagens, o celeiro, a casa dos bichos, a barragem. Depois, os pontos de parada do transporte acordados com as famílias - as bifurcações, o posto de saúde, as pequenas vilas e casas das crianças, as placas de sinalização da prefeitura (Aldeia Indígena e Morro do Canal), os sítios e as chácaras (Santa Bárbara, São Francisco de Assis, Lagoa Serena e Vista da Serra), a rua do 
armazém, o Centro de Recuperação para Alcoólicos Nova Esperança, a Igrejinha da Vila Santa Maria, o Cemitério, o Centro de Estudos Espiritualistas Casa de Obá, o Aras Estância Bonita.

Somavam-se a esses, os dizeres infantis sobre seus gostos, modos de viver a infância e o pensar sobre os laços familiares, escolares e de amizade, na relação com o lugar - "Meu pai tira peixe do açude. Lá é fundo... Eu sei nadar um pouco e queria ir até lá" (Raimundo, $3^{\circ}$ ano); "Do ladinho da minha casa é onde eu brinco de escolinha" (Isa, $2^{\circ}$ ano); "Da minha casa dá pra ver a escola, bem do alto. Às vezes fico espiando o recreio da tarde" (Gustavo, $3^{\circ} \mathrm{ano}$ ).

Tratava-se de um conjunto de falas significativas que expressava o senso de pertencimento, no sentido assinalado por Viñao Frago (1998),

[...] O espaço se projeta ou se imagina; o lugar se constrói. Constrói-se 'a partir do fluir da vida' e a partir do espaço como suporte; o espaço, portanto, está sempre disponível e disposto para converter-se em lugar, para ser construído. (VIÑAO FRAGO, 1998, p. 61).

Nesse sentido, as características do lugar se apresentavam como objeto de significação dos conteúdos curriculares, desde a referência as diferentes religiosidades e os traços étnico-culturais (matriz europeia, indígena e africana) demarcados - nas placas de sinalização, na igrejinha, na oferenda em frente ao cemitério -, passando pelos afetos entre as crianças e com suas famílias que as aguardavam nos pontos acordados, a protegê-las de cães ferozes ou acolhendo-as nos dias chuvosos com guarda-chuvas e galochas.

As crianças reportavam-se ao lugar com base no modo como memorizavam os caminhos por onde passavam - "a porteira da chácara onde eu moro e a casa do patrão que fica mais pra cima" (Daniel, $3^{\circ} \mathrm{ano}$ ); "a casa abandonada do meio do mato fica perto da minha" (Marco, $1^{\circ} \mathrm{ano}$ ); "pra lá daquela cerca mora o amigo do pai" (Carlos, $1^{\circ}$ ao); "a chacrinha da Gi fica antes da minha" (Aline, $\left.3^{\circ} \mathrm{ano}\right)$; "aquela árvore é onde eu espero o ônibus todos os dias" (Emilia, $2^{\circ} \mathrm{ano}$ ).

CASAS DA CAPOEIRA

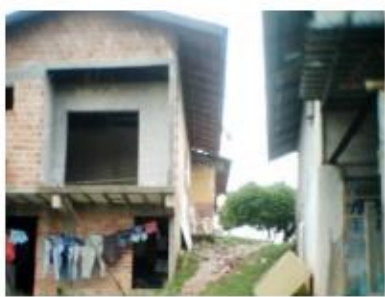

Casa das tias (Juliana, $1^{\circ}$ ano)

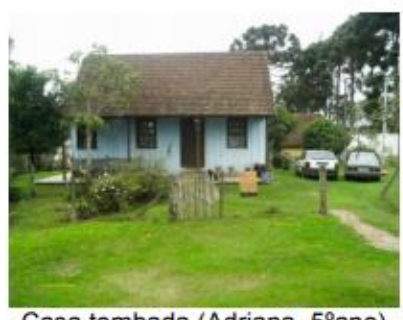

Casa tombada (Adriana, $5^{\circ}$ ano)

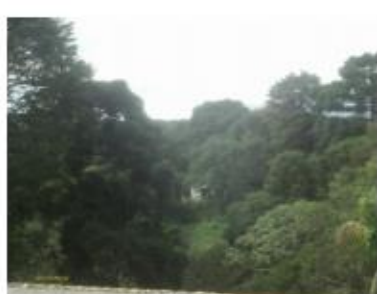

Casa abandonada (Gabriel, $4^{\circ} \mathrm{ano}$ )

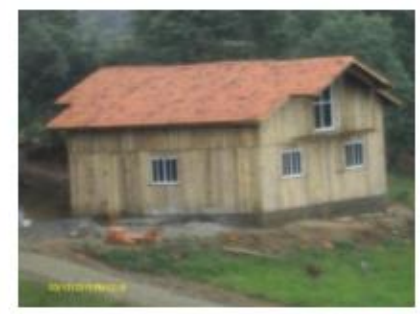

Casa em construção (Ângela, $5^{\circ}$ ano) 
Outro aspecto a ser destacado é que suas falas estavam em sintonia com o passado recente da região, a partir do qual se reconheciam parte de uma tradição - "Moro desde que eu nasci nesse lugar" (Luciana, $4^{\circ}$ ano); "É por ali que fica a grutinha da nona, com a santinha dentro" (Letícia, $4^{\circ}$ ano). Eram as crianças que explicavam que suas famílias e moradias pertenciam às primeiras ocupações da Colônia Santa Maria, e pelo tempo de permanência na região, sentiam-se culturalmente identificadas.

Diante de seus relatos seria possível que a escola registrasse com elas um pouco da história local, reforçando o patrimônio material e imaterial evocado e fazendo uso de documentos guardados pelas famílias. Suas narrativas poderiam compor, por exemplo, mapas e inventários dos caminhos percorridos e das histórias de suas famílias,

\footnotetext{
Minha casa já foi filmada várias vezes porque é tombada pelo patrimônio histórico. É de madeira e tem dois andares. Os quartos ficam lá em cima, são dois. Minha bisa veio da Itália no tempo das guerras. A igreja Santa Maria foi feita em mil novecentos e alguma coisa por imigrantes italianos e por brasileiros. Eu moro do lado dela. A vó e mais outra senhora são ministras dessa igreja. (Adriana, $5^{\circ} \mathrm{ano}$ ).
}

Outras crianças testemunhavam a dificuldade em morar distante das pequenas vilas. Sem vizinhos próximos, buscavam os bichos como companheiros. "Na chácara em que meu pai trabalha tem um gramado em que os cavalos ficam. O pequeno acabou de nascer. Não tem quase nenhum vizinho pra brincar" (Flavio, $4^{\circ}$ ano).

Entre os relatos de isolamento estavam aqueles que reforçavam a visão da cidade como algo distante, e da qual não se sentiam parte dada a dificuldade em usufruir dos equipamentos e serviços concentrados no espaço urbano. A menina Carolina se referiu à cidade de Piraquara como um espaço não transformado em lugar, diferentemente do terreno onde mora, brinca e convive com os primos, segundo ela formando uma grande família.

\footnotetext{
No dia em que eu tirei minhas fotos estávamos de saída para Piraquara, eu e minha mãe. Íamos pegar a calça do pai e comprar remédio. Estou sempre junto com as minhas primas. Moramos no mesmo terreno, cada uma com a sua casa e somos uma família só. (Carolina, $3^{\circ}$ ano).
}

E por fim, o lugar concebido como em construção, pois para falar dele era preciso descrever para expressar descobertas vindas do reconhecimento espacial e assim entender melhor um novo momento da própria existência no contexto familiar. Um aluno, recém-chegado, contou suas impressões e experiências,

Desde o ano passado estou morando nessa chácara. Tem uma casinha na árvore e lá pra baixo dá pra ver a Barragem. Costumo brincar no gramado com o cachorro, perto do galinheiro. Fico soltando pipa. Não têm muitas crianças por perto, só os cachorros. Já fui pescar com o pai na Barragem e tem bastante árvore com sombra. Na chácara tem horta, eucaliptos e muitas árvores. Paisagens bonitas para um dia de Sol. (Luan, $3^{\circ}$ ano). 
Entre as paisagens evocadas, a predileção pela barragem. Vista de uma pedra, da chácara em que se mora ou pela janela do ônibus, por mais por de uma vez foi lembrada como um lugar especial que guarda muitas histórias...

\section{A BARRAGEM VISTA DE UMA PEDRA}
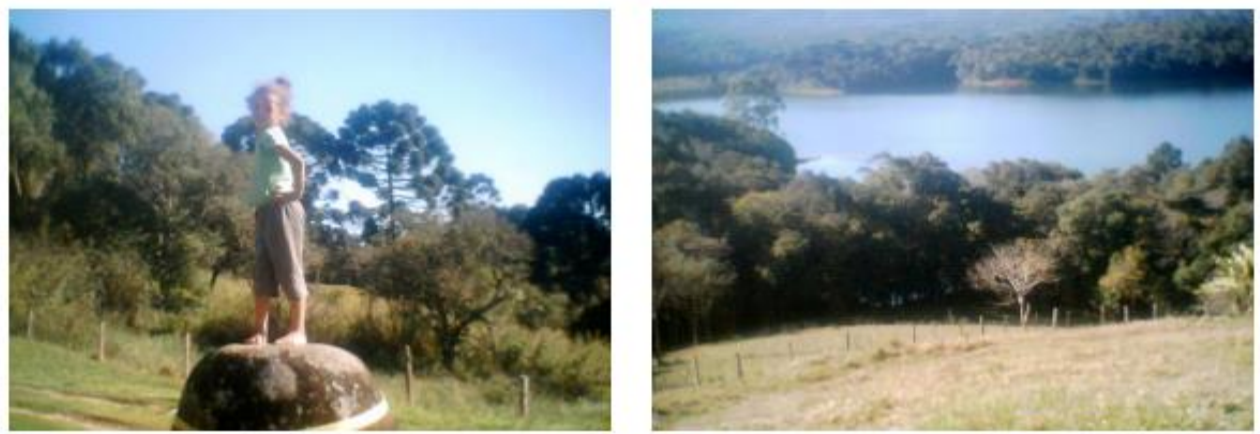

A pedra de onde dá para ver a Barragem e a vista da chácara onde eu moro

(Daniele, $2^{\circ}$ ano)

\section{HISTÓRIAS DE UM PASSADO RECENTE}

A recorrente referência à barragem permitiu à pesquisa transver ${ }^{16}$ a produção do conhecimento escolar na direção dos aspectos culturais do lugar ${ }^{17}$. Nessa leitura, junto dos dizeres infantis capturados do cotidiano, o audiovisual Conhecendo Piraquara havia permitido registrar histórias das gerações antigas, relativas aos mesmos caminhos percorridos, como mostrou Margarida ao rememorar o período de construção da barragem,

Foi triste. Triste que eu quase não podia parar aqui. Quase de acabar com a gente. Também eu morei 55 anos lá. $\mathrm{E}$ o meu marido nasceu e criou-se e morreu ali. E depois lá nós tínhamos tudo. Tinha os arvoredos. Bastante criação. Agora estou mais acostumada. (Conhecendo Piraquara, 2007).

O mesmo caminho contrastava rupturas relatadas por famílias que tiveram suas terras alagadas. Sinalizava na paisagem mudanças culturais profundas, as quais emergiam sob os escombros ambientais, pelas lentes fotográficas das crianças. Mudanças e permanências registradas nos costumes, no tempo de moradia na região, nas atividades, nas crenças, nas condições de trabalho.

\footnotetext{
16 Licença poética inspirada em Manuel de Barros, sobre a imaginação segundo o movimento ver-rever-transver o mundo. Num paralelo com a discussão metodológica suscitada por Freire (1987) se refere ao cotidiano codificado-refletido-transformado, ou em outros termos, às práticas de observação, registro da memória e mobilização social em torno do conhecimento, numa dada realidade.

17 Vale lembrar que esta região é conhecida por seus mananciais de água.
} 
Para auxiliar na codificação desse universo cultural, a escola contava com os conhecimentos históricos e geográficos sistematizados em seu currículo ${ }^{18}$. Esse documento reunia um repertorio metodológico especializado a ser acessado para mediar com as crianças a ressignificação dos caminhos percorridos. Nesse movimento, os laços entre gerações, as mudanças na paisagem, as tradições familiares de novos e antigos moradores, as edificações emblemáticas e as práticas sociais de trabalho e de lazer ontem e hoje, entre outros conteúdos, poderiam se tornar potenciais objetos de estudo no processo de escolarização.

\section{A ESCOLA COMO LUGAR CONQUISTADO}

$\mathrm{Na}$ investigação de conteúdos para a ressignificação do cotidiano do lugar, havia também os relatos dos esforços das antigas e novas gerações em busca da escola. Dizeres remetidos à luta das famílias pelo acesso ao conhecimento. Isso mostrou Batista ao comentar como era estudar na Colônia lá pelos anos de 1930 .

A nossa professora era Clementina Cruz. As meninas varriam a sala e os meninos, o pátio. Estava sempre limpinho. Começava uma hora e terminava às cinco. A família estava na roça e a gente saía para levar o almoço e depois voltava correndo para a escola. Andava dois quilômetros mais ou menos.

Do mesmo modo como testemunharam oralmente os mais velhos, as atuais gerações registravam seu ir e vir até a escola e, em seus dizeres sobre o ato de estudar, as crianças fizeram menção ao próprio futuro escolar, alinhado ao dos irmãos e irmãs que se deslocavam até o centro da cidade para cursar o Ensino Médio.

Tivemos a oportunidade de acompanhar ex-alunos do ensino fundamental em uma das rotas do transporte. lam para colégios do centro da cidade de Piraquara. $\mathrm{Na}$ ocasião, ficamos refletindo sobre as oportunidades educacionais buscadas por essas famílias. Verificamos que os relatos endossavam a questão do direito a mobilidade espacial, dado o relativo isolamento da região. Indagávamos se a oportunidade de estudar verbalizada como quesito de um futuro melhor, não acabaria relativizada por um sistema de vida, pacato, precário sob o ponto de vista do acesso aos bens culturais concentrados no espaço urbano.

Em certa medida um sistema de vida sem muitas variações, pois assim faziam os irmãos mais velhos e, antes deles, os pais e talvez os avós. Em relação à escola e às expectativas sociais, tratavase de travessias pessoais e intergeracionais ${ }^{19}$, ao encontro da manutenção da simplicidade do modo de vida local, mas também em contraste com as necessidades do presente no que se refere ao pensar o futuro das novas gerações.

\footnotetext{
18 Durante a pesquisa acessamos a proposta pedagógica curricular para as áreas do conhecimento ministradas na escola.

19 Estamos usando intergeracional para demarcar a produção das infâncias da Capoeira dos Dinos no contexto de suas inserções sócio familiares ontem e hoje. Em um plano geral, refere-se à experiência social que se perpetua, mas que ao mesmo tempo muda, de modo que as histórias de vida acessadas configuram um tecido comunicativo de proximidades e de diferenças entre os sujeitos (velhos, jovens e crianças), entrecruzando no tempo presente o passado e o futuro do lugar.
} 
Isso foi verbalizado por duas crianças ao expressarem suas fantasias sobre profissões futuras. De um lado, o menino desenhista que queria ser engenheiro para projetar carros de luxo fora do seu lugar de origem, de outro, o menino que queria continuar morando ali, tornando-se caminhoneiro como o pai.

Junto dessas expectativas, havia também demandas advindas da chegada de novas pessoas, muitas delas atraídas pelas grandes propriedades da região. Eram filhos de chacareiros, vindos de outras cidades paranaenses em busca de trabalho. Circunstância, possivelmente, geradora de diferenças entre os moradores mais antigos, com suas tradições, e as vivências das famílias instaladas há menos tempo.

Desse modo, nos referentes culturais levantados, identificamos mudanças sociais em curso, observadas nos dizeres dos velhos, crianças e jovens. Ainda que o sistema de vida local os identificasse sob muitos aspectos, os descritores acionados trouxeram uma realidade em transformação. Sinalizava infâncias semelhantes, mas também diferenças entre as crianças, suas famílias e suas relações com o lugar.

\section{CONSIDERAÇÕES FINAIS}

Tomando por base a leitura de Paulo Freire (1987) com os dizeres e fotografias das crianças esse artigo esclareceu a experiência sociocultural que perpassa o desvelamento do cotidiano, de onde o tema gerador do conhecimento se anuncia. Os referentes culturais oriundos dos trajetos casasescola foram pensados como a serviço da construção de um currículo culturalmente integrado. Dentro do recorte desse artigo, um repertório considerável pode ser disponibilizado à mediação da escola, analisado sob a confluência histórica incidente no cotidiano do lugar.

Com base no excerto de dizeres infantis, bem como na própria observação do cotidiano escolar, foi possível reflexionar o diálogo lacunar entre a escola e o contexto de vida dos alunos. Porém, antes disso, esclarecemos que os referentes culturais analisados nesse artigo, não são prescritivos, tampouco desejam corroborar com a crítica superficial da escola, ao contrário, objetivam apenas denotar a discussão metodológica de um ensino contextualizado, ponto a partir do qual de agora em diante demarcamos nossas conclusões finais.

A escola não se lançou numa construção que levasse em consideração a potência da experiência educativa extramuros porque esteve restrita a repetição de sua própria regularidade, ao mesmo tempo em que era condicionada por determinantes estruturais nela incidentes, tal como demonstrou a sujeição das rotinas pedagógicas aos horários do transporte escolar, exaustivo para a maioria das crianças. No contexto escolar havia ressalvas quanto a possibilidade de realizar a ação pedagógica extramuros, seja porque os deslocamentos eram difíceis ou porque não estava clara a possibilidade de aproximação do currículo com as características do lugar segundo as crianças. 
Porém, ainda que não fosse essa a orientação da escola ${ }^{20}$, ao menos não enquanto componente central da organização dos turnos regulares e de seu projeto de contra turno, não havia em suas dependências alunos em abstrato, mas crianças fisicamente presentes com seus existires histórias, tradições, vivências e leituras de mundo -, diversidade que a pesquisa logrou capturar.

Nesse impasse, a experiência escolar parecia coadunar com a crítica negativa do cotidiano (HELLER, 1987), posto que se mantivesse submissa às padronizações do ensino massificado. De onde a diversidade da experiência social das crianças contrastava com a situação limite de uma escola enclausurada em sua própria edificação, como se condenada a perpetuar práticas pedagógicas alheias ao escutar seus alunos.

Entretanto, não se trata de indagar a escola para endossar a crítica negativa do seu cotidiano, reduzindo-a ao estigma de incapaz de mudar sua própria realidade, mas de, através da assunção de seus contraditos, ir ao encontro dos inéditos viáveis ou ao menos das suas tentativas de inovação, por exemplos quando constatamos a adesão ao Programa Mais Educação e a iniciativa de produção do audiovisual Conhecendo Piraquara. Conforme instiga a teoria da ação dialógica de Freire (1987), as narrativas infantis convidavam a escola a se por em comunicação com a vida de seus alunos, ensinando-os não pelo conteúdo ministrado em si mesmo, mas tendo em vista politizar o processo pedagógico, segundo a mobilização social em uma realidade concebida em transformação.

Nessa ótica, a pesquisa compreendeu a necessidade de outra forma de educar, a luz da crítica positiva do cotidiano escolar. Daí porque os referentes culturais trazidos pelas crianças se destacavam como inéditos viáveis, disponíveis à mediação pedagógica, a partir dos quais se tornaria possível criticar a escola para transformá-la. Assim, adentrando a discussão metodológica de Freire (1987), reportamo-nos a crítica ao formalismo e verbalismos próprios da educação bancária, indo à busca do tema gerador para inaugurar outra Pedagogia. Nessa abordagem a escola não é um lugar a ser descartado e nisso concordavam as crianças e suas famílias, posto que, por mais de uma geração foi lembrada como representativa da luta dos grupos populares pelo acesso ao conhecimento, configurando-se assim como destinatária de esforços coletivos e de expectativas de um justo e digno viver.

Escutando as crianças foi possível verificar o quão distante o ensino convencional está dos centros de interesse manifestos por elas. Ao expressarem suas preferências e referências sobre o lugar onde moram e estudam elas verbalizaram significativas palavras geradoras - barragem, trajetos, histórias, cultura, entre outras. Com essas palavras foi possível mapear os caminhos diariamente percorridos para ressignificá-los, de onde a questão do direito a mobilidade espacial veio como tema gerador do conhecimento, surgido do contexto investigado.

A partir dele seria possível eleger conteúdos que pudessem conduzir as crianças ao estranhamento diante do já conhecido, a fim de que elas mesmas conheçam em profundidade suas próprias histórias, aparentemente banais, reportadas as paisagens e detalhes observados durante os encontros, brincadeiras, cantorias e comentários diários nos trajetos entre as casas e a escola.

\footnotetext{
${ }^{20}$ Arroyo (2012) indaga sobre o quanto a escola conhece ou desconhece o modo como se vive ou mal se vive a infância. Instiga o pensar sobre como esse saber se converte ou não em mediações pedagógicas afirmativas.
} 
Também seria viável mapear pontos de cultura representativos dos diferentes modos de viver a infância, de tal feita que as crianças pudessem se debruçar sobre os conteúdos por elas mesmas fotografados, acompanhar o registro de suas histórias de vida e, em interlocução com as histórias do passado, dimensionar expectativas sociais do presente.

Poderiam inclusive, com a mediação da escola, seguir na direção de outros lugares, pessoas e histórias da Piraquara que está lá, e/ou aprofundar suas raízes, ao encontro das vozes de um passado remoto ainda aqui, evocado na repetição de um presente e futuro corriqueiro, rememorado nas vivências das novas gerações daqueles que sempre ali estiveram e também pelos filhos das famílias há menos tempo instaladas na região.

Entre as noções e conteúdos curriculares implicados nessa produção escolar, identificamos: a) as pertenças e as referências de mundo das crianças a partir da convivência familiar e dos círculos de socialização para além da morada; b) a individualidade construída segundo tempos e espaços de afirmação em diferentes grupos de convívio - irmãos e primos, amigos e vizinhos, igreja, escola, lugares frequentados; c) as noções de representação espacial e temporal (dentro/fora, perto/longe, antes/depois, ontem/hoje, rotinas diárias); d) as características culturais do lugar (a partir de laços entre gerações, da mudança na paisagem, dos objetos antigos guardados pelas famílias, das antigas e novas tradições, das edificações emblemáticas, das práticas sociais de trabalho e de lazer); e) a relação entre presente, passado e futuro na construção social do lugar; f) o mapeamento dos equipamentos, serviços públicos disponíveis e pontos de referência; g) a relação de proximidade e de afastamento com o centro da cidade de Piraquara.

Desse modo, partido dos referentes culturais levantados pelas crianças, esse artigo trouxe um mapeamento dos conteúdos curriculares implicados nos trajetos casas-escola. Além disso, considerou o direito à mobilidade como tema gerador do conhecimento, com o qual reconhecemos a viabilidade da construção de práticas educativas culturalmente integradas, condizentes com a diversificação do ensino e capazes de dimensionar o cotidiano do lugar para além de suas repetições. 


\section{REFERÊNCIAS}

1. ARROYO, Miguel. O direito a tempos e espaços de um justo e digno viver. In: MOLL, Jaqueline (org). Caminhos da educação integral no Brasil: direito a outros tempos e espaços educativos. Porto Alegre: Penso, 2012.

2. BARROS, Manoel de. Livro sobre nada. Rio de Janeiro: Record, 1996.

3. BAIERSDORF, Márcia. Notas para uma educação integral: participação das crianças da região da Capoeira dos Dinos (PR) na construção da experiência de mais tempo da escola em que estudam. Universidade Federal do Paraná: 2017.

4. BENJAMIN, Walter. Reflexões sobre a criança, o brinquedo e a educação. São Paulo: Duas Cidades, Editora 34, 2002. Rua de mão única: infância berlinense. Belo Horizonte: Autêntica, 2013.

A hora das crianças: narrativas radiofônicas. Tradução Aldo Medeiros. Rio de Janeiro: NAU, 2015.

7. BRASIL. Portaria n. 17, de 20 de abril de 2007. Diário Oficial da União. Brasília, DF, 24 abr. 2007. Decreto n. 7.083, de 27 de janeiro de 2010. Diário Oficial da União. Brasília, DF, 27 jan. 2010. Portaria n. 1.145, de 10 de outubro de 2016. Diário Oficial da União. Brasília, DF, 11 out. 2016.

10. DUBET, François. Sociologia da experiência. Tradução de Fernando Tomaz. Lisboa: Instituto Piaget, 1994.

11. GARCIA, Tania Maria Figueiredo Braga. Pesquisa em educação: confluências entre Didática, História e Antropologia. Educar em Revista. Curitiba: UFPR, n. 42, p. 173- 191, out/dez 2011.

12. EZPELETA, Justa. Pesquisa participante. São Paulo: Cortez: Autores Associados, 1989.

13. FREIRE, Paulo. Pedagogia do oprimido. Rio de Janeiro: Paz e Terra, 1987. . Educação como prática da liberdade. Rio de Janeiro: Paz e Terra, 1999.

15. HELLER, Agnes. Sociologia de la vida cotidiana. Barcelona: Ediciones Peninsula, 1977. 
16. IBGE. Instituto Brasileiro de Geografia e Estatística. Cidades. (Ferramenta de busca) Rio de Janeiro: O Instituto, 2016.

17. KRAMER, Sonia. Autoria e autorização: questões éticas na pesquisa com crianças. Cadernos de Pesquisa. São Paulo, n.116, p. 41-59, jul.2002.

18. LARROSA, Jorge. Notas sobre a experiência e o saber de experiência. Revista Brasileira de Educação. n.19, p. 20-28, jan/fev/mar/abr 2002. Pedagogia profana: danças, piruetas e mascaradas. Tradução Alfredo Veiga Neto. Belo Horizonte: Autêntica, 2015.

20. PIRAQUARA. Prefeitura Municipal. Conhecendo Piraquara. Paraná, 2007.

21. ROCKWELL, Elsie (org.). La escuela cotidiana. México: Fondo de Cultura Económica, 1997.

22. VIÑAO FRAGO, Antônio e ESCOLANO, Agustín. Currículo e subjetividade: a arquitetura escolar como programa. Rio de Janeiro: DP\&A, 1998.

\section{Márcia Baiersdorf}

Professora do Setor de Educação da UFPR, Departamento de Planejamento e Administração Escolar (DEPLAE), Organização do Trabalho Pedagógico.

\section{Marília Torales Campos}

Professora Doutora da Universidade Federal do Paraná.

\section{Com citar este documento:}

BAIERSDORF, Márcia; CAMPOS, Marília Torales. Leitura de Paulo Freire com infâncias: trajetos casas-escola como tema gerador do conhecimento. Reflexão e Ação, Santa Cruz do Sul, v. 28, n. 1, jan. $2020 . \quad$ ISSN 1982-9949. Disponível em: <https://online.unisc.br/seer/index.php/reflex/article/view/12939>. Acesso em: doi:https://doi.org/10.17058/rea.v28i1.12939. 